\title{
Minimizing Honey Bee Exposure to Pesticides ${ }^{1}$
}

\author{
J. D. Ellis, J. Klopchin, E. Buss, L. Diepenbrock, F. M. Fishel, W. H. Kern, C. Mannion, E. McAvoy, L. \\ S. Osborne, M. Rogers, M. Sanford, H. Smith, B. S. Stanford, P. Stansly, L. Stelinski, S. Webb, and
} A. $\mathrm{Vu}^{2}$

\section{Introduction}

Growers and pesticide applicators have a number of options when faced with a pest problem: do nothing, or apply some type of cultural, chemical, biological, or physical method to mitigate the damage. The action to be taken should be chosen after weighing the risks and benefits of all available options. There are many situations where pest control is necessary and chemical controls must be used. Certain chemistries of insecticides, fungicides, and herbicides are known to have negative and long-term impacts on bees, other pollinators, and other beneficial arthropods. Fortunately, there are pesticides that have minimal impacts on pollinators and beneficial organisms. The pollinator-protection language that is required to be on US pesticide labels outlines how best to minimize these impacts. The United States Environmental Protection Agency (EPA) works to protect bees and other pollinators by conducting risk assessments and partnering with federal, state, and international partners to identify ways to reduce pesticide exposure to beneficial pollinators, while including appropriate label restrictions to safeguard pollinators, the environment, and humans. More information can be found here: epa.gov/pollinator-protection. The bottom line is that the label is the law - it must be followed.

\section{Pollinator Importance}

The western honey bee (Apis mellifera, Figure 1) is conceivably the most important pollinator in Florida and American agricultural landscapes (Calderone 2012). Over 50 major crops in the United States and at least 13 in Florida either depend on honey bees for pollination or produce more yield when honey bees are plentiful (Delaplane and Mayer 2000). Rental of honey bee colonies for pollination purposes is a common management strategy for growers of pollinator-dependent crops. Thus, bee colonies are moved extensively across the United States for use in multiple

1. This document is ENY-162, one of a series of the Department of Entomology and Nematology, UF/IFAS Extension. Original publication date March 2014. Revised December 2020. Visit the EDIS website at http://edis.ifas.ufl.edu.

2. J. D. Ellis, Gahan endowed professor, Department of Entomology and Nematology; J. Klopchin, former Extension technician, Department of Entomology and Nematology; E. Buss, associate professor, Department of Entomology and Nematology; L. M. Diepenbrock, assistant professor, Department of Entomology and Nematology, UF/IFAS Citrus Research and Education Center; F. M. Fishel, former professor, Agronomy Department, and former director, Pesticide Information Office; W. H. Kern Jr., associate professor, Department of Entomology and Nematology, UF/IFAS Ft. Lauderdale REC; C. Mannion, associate professor, Department of Entomology and Nematology, UF/IFAS Tropical REC; E. McAvoy, UF/IFAS regional vegetable Extension agent IV emeritus; L. S. Osborne, professor, Department of Entomology and Nematology, UF/IFAS Mid-Florida REC; M. Rogers, former associate professor, Department of Entomology and Nematology, UF/IFAS Citrus REC; M. Sanford, professor emeritus, Department of Entomology and Nematology; H. Smith, assistant professor, Department of Entomology and Nematology, UF/IFAS Gulf Coast REC; P. Stansly, professor (deceased), Department of Entomology and Nematology, UF/IFAS Southwest Florida REC; L. Stelinski, professor, Department of Entomology and Nematology, UF/IFAS Citrus REC; S. Webb, associate professor, Department of Entomology and Nematology; A. Vu, Extension coordinator, Department of Entomology and Nematology; B. S. Stanford, Assistant Bureau Chief, Florida Department of Agriculture and Consumer Services; UF/IFAS Extension, Gainesville, FL 32611.

Use pesticides safely. Read and follow directions on the manufacturer's label.

The Institute of Food and Agricultural Sciences (IFAS) is an Equal Opportunity Institution authorized to provide research, educational information and other services

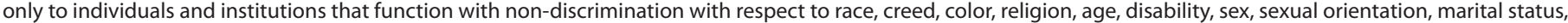
national origin, political opinions or affiliations. For more information on obtaining other UF/IFAS Extension publications, contact your county's UF/IFAS Extension office. U.S. Department of Agriculture, UF/IFAS Extension Service, University of Florida, IFAS, Florida A \& M University Cooperative Extension Program, and Boards of County Commissioners Cooperating. Nick T. Place, dean for UF/IFAS Extension. 
crops every year. There are nearly 5,000 registered beekeepers in Florida managing a total of more than 620,000 honey bee colonies and producing between 10-20 million pounds of honey annually.

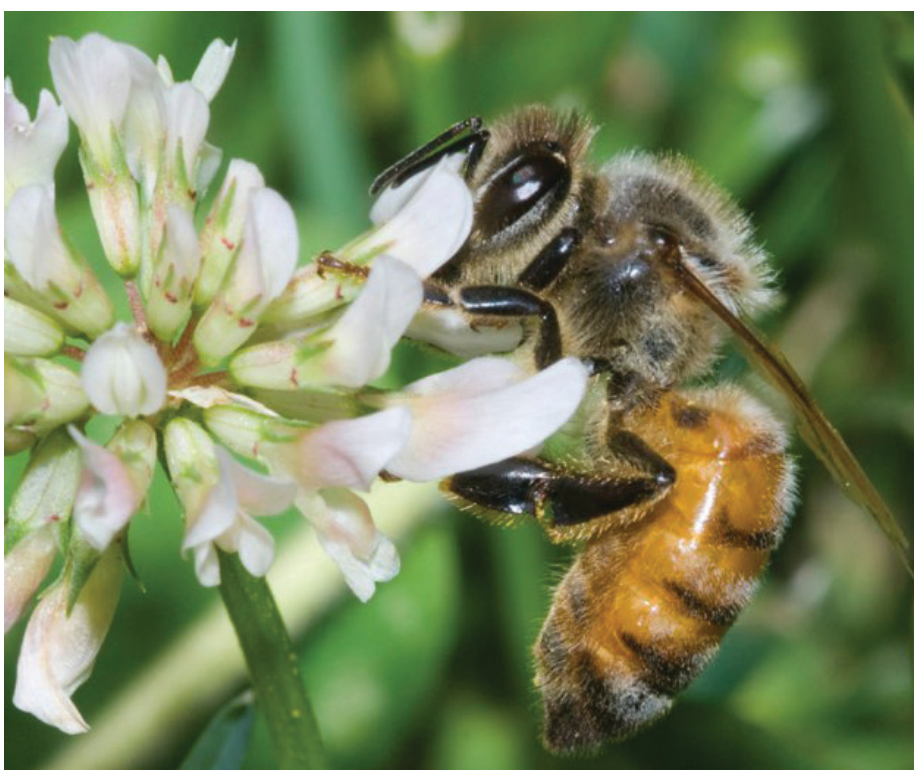

Figure 1. The western honey bee, Apis mellifera, collecting nectar from a flower.

Credits: Susan E. Ellis, littleladiesofthehive.com (used with permission)

Growers also use other managed bee species, such as bumble bees (Bombus spp., Figure 2), to provide field and greenhouse crop pollination services. Additionally, there are more than 315 species of wild/unmanaged bees in Florida that play a role in the pollination of agricultural crops and natural and managed landscapes. These include mining bees, mason bees, sweat bees, leafcutter bees, feral honey bees, and carpenter bees, among others. However, none of these wild bees are managed like honey bees or bumble bees.



Figure 2. A bumble bee (Bombus spp.) collecting nectar from a blueberry flower.

Credits: Katie Buckley, University of Florida

\section{Pollinators and Pesticides}

Given the evidence of lethal and sublethal effects of several pesticide groups and compounds on insect pollinators, protecting honey bees and other pollinators from pesticide impacts is important to the sustainability of agriculture. Consequently, pesticide applicators must determine if there is a clear hazard to managed or wild populations of bees prior to applying a pesticide. Potential exposure of bees to pesticides can vary greatly depending on the type of pesticide, formulation, application method, label restrictions, and other factors. The goal in using a pesticide is to achieve maximum benefit (success) with minimum negative impact, and these factors should always be considered during pesticide use.

This publication is written (1) to help assure the sustainability of both bees and agriculture by informing beekeepers, pesticide users, and the general public about the often complex relationship between pollinators (specifically honey bees) and pesticides; (2) to offer guidance for improved communication between beekeepers and pesticide applicators; (3) to offer strategies for growers and other applicators to reduce risks when using pesticides; and (4) to provide clarity in laws, labeling, and associated definitions.

\section{Pesticide Use in Florida Agriculture}

Florida agriculture is a multi-billion dollar industry, occupying over nine million acres of the state's total land. Much of the United States depends on Florida for its winter supply of produce. However, Florida's favorable environment also supports a multitude of crop pests, and their management is a year-round component of agricultural production. Pests include various insects, mites, fungi, weeds, and other undesirable organisms that reduce crop yield. Collectively, these pests can cause severe damage, and some also spread diseases that can result in significant crop and financial losses. Integrated pest management (IPM) - a framework using pest-monitoring strategies and rational decision-making to reduce unnecessary pesticide use by integrating chemical, physical, cultural, and biological pest control tactics-has been systematically implemented in many of Florida's major cropping systems. Nevertheless, Florida farmers continue to rely heavily upon pesticides for high-yielding, cost-effective crop production. A summary on agricultural pesticide use in Florida can be found here: https://www.nass.usda.gov/Surveys/Guide_to_NASS_Surveys/Chemical_Use/. Unfortunately, it is not always possible to make pest-control decisions about high-value crops based on honey bee activity. Therefore, there is frequent risk of exposure. 


\section{Definitions: Acute and Chronic Toxicity}

In general, toxicity refers to the ability of a substance (a pesticide in this case) to produce adverse effects on an organism and its normal function. Acute toxicity refers to systemic damage as a result of a single or short-term exposure to the chemical. A pesticide with a high acute toxicity can be deadly in small amounts. The signal words found on all pesticide labels are based on the acute toxicity of the pesticide to mammals (e.g., humans), not pollinators. Therefore, acute toxicity of pesticides to honey bees requires much less of the pesticide's active ingredient.

For pollinators, acute toxicity from pesticides can result from either direct exposure (e.g., pesticide spray), exposure to residues on foliage and/or flowers, or consumption of the pesticide in nectar or pollen (subacute or dietary exposure) (Gradish et al. 2019; Thompson 2001).

Toxicity to pollinators is typically determined using honey bees in oral or contact toxicity studies. Pesticide formulations are considered highly toxic to bees if the $\mathrm{LD}_{50}$ (the lethal dose that kills $50 \%$ of the test organisms) is $<2 \mu \mathrm{g} /$ bee and moderately toxic if the $\mathrm{LD}_{50}$ is between 2 and $11 \mu \mathrm{g} /$ bee. If the $\mathrm{LD}_{50} \geq 11 \mu \mathrm{g} / \mathrm{bee}$, then the pesticide is considered practically non-toxic to bees at an acute level. Information on pesticide labeling and protection of pollinators can be found here: https://edis.ifas.ufl.edu/pi271.

Residual toxicity refers to pesticides that have residues that are expected to cause target pest and non-target organism mortality. Many pesticide applicators prefer to use products with longer residual activity because they can provide extended protection of the target pests. Pesticide residues, often left on the foliage of plants, decrease in toxicity over time. The residual toxicity is determined with a bee residue study (honey bee or other bee species). For these studies, a crop is sprayed with the pesticide at the maximum label rate. Foliage is collected from the field (e.g., at 3, 8, and 24 hours after application) and is introduced to caged bees. Bee mortality is measured for each exposure of treated foliage to determine the toxicity of the residues over time. Those pesticide products that have residues that are toxic to bees for greater than 8 hours are considered to have "extended residual toxicity." Pesticide labeling language to protect pollinators like honey bees is based on both direct acute toxicity (i.e., toxicity group) and on residual toxicity (Table 1). Pesticide labeling information can be found here: https://edis.ifas.ufl.edu/topic_pesticide_labeling.
Table 1 provides a general template for the relationship between pesticide toxicity groupings and the corresponding pollinator protection label statements found on pesticide products. It is important to note that the EPA provides new labeling on Pollinator Protection Labeling found here: https://www.epa.gov/pollinator-protection/newlabeling-neonicotinoid-pesticides. In some cases, there may be variations or exceptions from Table 1 for specific pesticide labels. Another mode of exposure not currently addressed by the EPA on pesticide labels is the potential dietary exposure of systemic pesticide residues in honey and bee bread (a nectar/pollen mixture that bees eat). For information on what the EPA is actively doing for their pollinator risk assessments, see: https://www.epa.gov/ pollinator-protection/epa-actions-protect-pollinators.

Finally, chronic toxicity refers to harmful effects produced by long-term or repeated exposure to pesticides that may impact survival, growth, or reproduction of individual bees or entire colonies. Less is known about the chronic toxicity of pesticides to honey bees, mostly due to the difficulty in determining the subtle effects that may impact individual bees or colonies. Although chronic toxicity warnings generally are not listed on pesticide labels for pollinators, the EPA is considering the potential effects of pesticides that go beyond simple acute toxicity of contact exposure to foragers. The EPA is also considering dietary exposure (consumption of contaminated honey and bee bread), larval toxicity, chronic toxicity to adults and larvae, and field effects studies that look at impacts to whole colonies (EPA Pollinator Risk Assessment Framework White Paper: http://www.regulations. gov/\#!documentDetail;D=EPA-HQ-OPP-2012-0543-0004).

\section{Routes of Exposure: Outside the Hive}

Field bees are the individuals most likely to be exposed to pesticides because they forage outside the hive. While foraging, honey bees collect pollen from flower anthers and nectar from plant blossoms and extra-floral nectaries (Figure 3). Foraging honey bees may fly $2-5$ miles $(3.2-8 \mathrm{~km})$ from their colony in any direction in search of resources (Winston 1987). Thus, an actively foraging colony can cover an area up to 80 miles $^{2}$ or $201 \mathrm{~km}^{2}$ (within a 5 -mile $[8-\mathrm{km}]$ radius of the hive). Despite this large possible foraging range, honey bees do tend to forage on the richest, most nutrient-dense and abundant food sources closest to the hive. Honey bees typically forage during daylight hours when temperatures are above $55^{\circ} \mathrm{F}$ $\left(12.8^{\circ} \mathrm{C}\right)$, and they reduce their activity at dawn and dusk 
and during inclement weather. They forage for nectar and pollen and even collect water from sources close to their colonies (Figure 4). Different hives in the same location can forage on different food sources. As a result, hive exposure to environmental toxins can vary by hive, depending on the forage source and the pesticide residue it may contain.

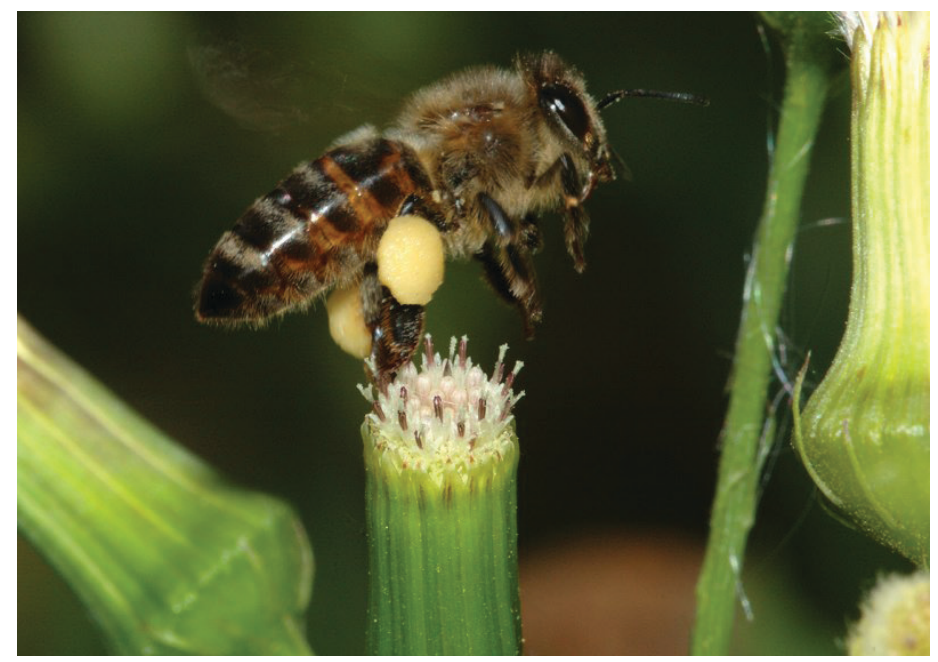

Figure 3. Honey bees collect pollen from flowers and pack it on their back legs to take back to the colony to consume. The flower is pollinated as a result.

Credits: Susan E. Ellis, littleladiesofthehive.com (used with permission)

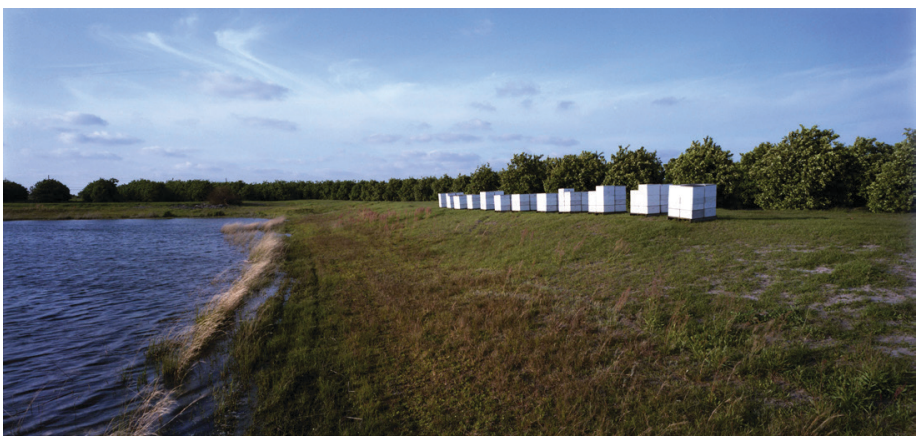

Figure 4. Honey bee colonies placed next to a citrus grove to produce a citrus honey crop. Bee exposure to pesticides can occur when they drink water, such as that in the irrigation pond shown in this figure, or when foraging on the crop.

Credits: Florida Department of Agriculture and Consumer Services

It is during the foraging hours and points of contact (foliage, pollen, nectar, water, and propolis) that bees are most likely to be exposed to pesticides and other environmental toxins present in their foraging area. Consequently, foliar surfaces, soils, and exposed pollen or nectar that have received direct spray, dusting, or other direct exposure to pesticides provide an immediate route of exposure to field or foraging bees. Systemic pesticides, which may be applied by soil treatment, seed treatment, direct injection, or foliar applications, are translocated within the treated plants and may be expressed in the nectar, pollen, or various plant tissues or excreted as honeydew from plant-sucking insects (Johnson 2015). Bees can be affected by pesticides outside the hive acutely (they die of toxic exposure before returning to the nest) or chronically (they carry pesticide residues with them back to the nest where the residues may produce long-lasting, sublethal effects) (Sanchez-Bayo and Goka 2014). Exposure to certain insecticides may have no detrimental impact at all on bees.

\section{Routes of Exposure: Inside the Hive}

Honey bees can also be exposed to pesticides purposely administered to their colonies. The managed honey bee colony suffers from a number of invading insect pests, parasites, and pathogens. Two of the major honey bee pests that have historically required in-hive applications of synthetic pesticides are the nest-invading small hive beetle (Aethina tumida) and the parasitic Varroa mite (Varroa destructor). These two pests have posed immediate and lingering effects on honey bee colonies in North America because the honey bee has had little time (since the 1990s for small hive beetles and the 1980s for Varroa) to develop defenses against them.

Beekeepers have relied mainly on chemical options to combat the hive beetle. Some IPM tactics such as traps and apiary care have become increasingly popular in hive beetle control tactics. Traditionally, Varroa have been controlled chemically with tau-fluvalinate (a pyrethroid) and coumaphos. Both were initially efficacious against the mite; however, many Varroa populations have developed resistance to these two pesticides (Johnson et al. 2010). The formamidine pesticide, amitraz (Apivar ${ }^{\circledR}$ ), is now a popular active ingredient used by beekeepers against the mite. Additional active ingredients used against Varroa include formic acid, hop beta acids, oxalic acid, and thymol. Many of these in-hive applied pesticides and their residues have been detected inside various hive components, resulting in both acute and chronic bee exposure.

\section{Pesticide Integration into the Hive}

Honey bees collect nectar and pollen and consume honey (a nectar derivative, Figure 5) and bee bread, a pollen/ nectar mixture stored in combs and later fed to developing bees as food (Figure 6). Storage of contaminated bee bread and honey can lead to contaminated wax and royal jelly. Contaminated bee bread and honey are mixed into brood food, which is composed of glandular secretions of worker bees, and fed to developing larvae. Wax is used to construct the hexagonal cells (the "comb") in which queens lay eggs, the brood develops, and honey and bee bread are stored. Beekeepers who repeatedly use contaminated comb 
continue to expose bees to varying levels of pesticides and their metabolites (breakdown products). Many pesticides are lipophilic (wax-loving), a quality that makes them likely to remain in beeswax. Wax slows the degradation of these materials, thus possibly further increasing the exposure of bees to pesticides. Investigators surveying US honey bee colonies for pesticide residues have found residues from insecticides, herbicides, miticides, and fungicides in the various hive components (Mullin et al. 2010; Ostiguy et al. 2019). These and other studies highlight the reality of honey bee exposure to pesticides and emphasize the need for pollinator exposure mitigation programs.

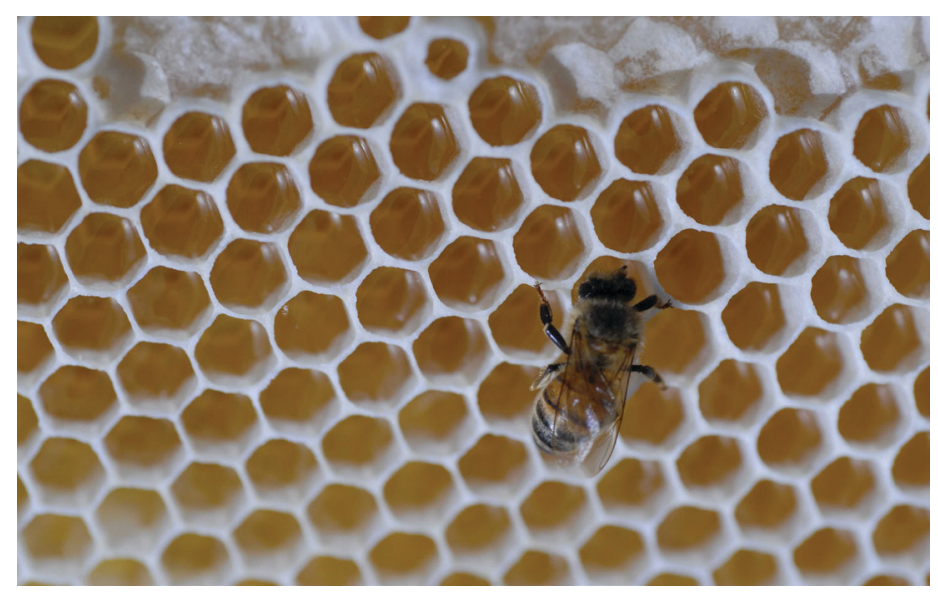

Figure 5. Nectar stored in the wax comb. The nectar will "ripen" into honey, which is consumed by the bees as their carbohydrate source. Credits: University of Florida

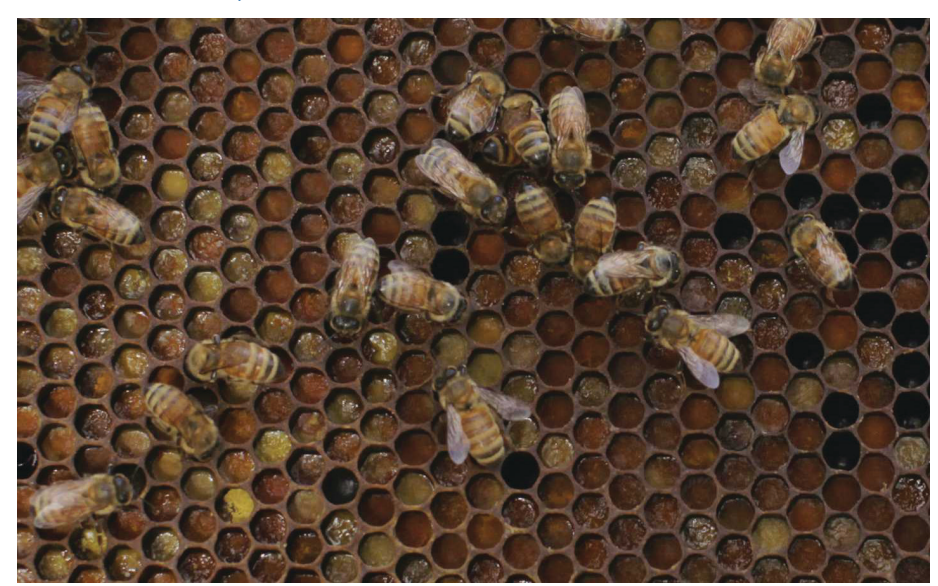

Figure 6. Bee bread stored in the wax comb.

Credits: James Hill (used with permission)

\section{Effects of Pesticides on Bees}

Acute exposure to pesticides can kill individual honey bees and entire colonies immediately or within hours of exposure. Chronic pesticide exposure may include lethal and sublethal effects on the brood, workers, drones, and queens, who may be killed or rendered infertile (Fisher and Rangel 2018). Within an individual bee, certain pesticides and their associated metabolites can attach to, alter, or destroy cells in the gut, brain, or other tissues, thus affecting the bee's physiology and behavior. Sublethal effects of pesticides include physiological effects that impact enzyme activity and brain activity that lead to impairment of olfaction, learning, and memory; and behavioral effects on motor activity that lead to alterations in navigation, orientation, and feeding behavior (Wu et al. 2011). Reproductive effects may include reduced sperm viability in drones that causes poor mating for queens and disruption of ovary activation in the developing queen. Compounded sublethal effects of individual bees may result in colony-level effects, such as poor brood build-up, poor nourishment, frequent queen replacement (supersedure), low overwintering success, and, potentially, colony demise. Sublethal effects of pesticides on bees and other pollinators is a growing research field. See Johnson et al. (2010) for an overview of pesticides and honey bee toxicity.

\section{Pesticide Regulations}

At the federal level, the EPA oversees the regulation of pesticides. The Federal Insecticide, Fungicide, and Rodenticide Act (FIFRA) is the primary law establishing how the EPA is to register pesticides and oversee their regulation. The framework established in FIFRA for pesticide regulation gives primacy to states that have met certain criteria and provides for oversight by the EPA. The Florida Department of Agriculture and Consumer Services (FDACS) is the state lead agency for pesticide regulation in Florida. The EPA and FDACS work together to regulate pesticides.

Chapter 487, Florida Statutes is the primary state law overseeing pesticide registration and regulation. Chapter 487 serves to regulate the distribution, sale, and use of pesticides and to protect people and the environment from the adverse effects of pesticides. In some instances, Florida law and rules may be more stringent than federal regulations and set forth Florida-specific requirements for licensing and enforcement of pesticide use. It is this chapter that outlines Florida's state-specific laws regarding pesticides and that, together with pesticide product label instructions, determines how pesticides are to be used in Florida. Florida's pesticide laws and rules do not specifically address the protection of honey bees or pollinators, but interpretations of sections can and should be used in good judgment for that purpose.

\section{Pollinator Language on Pesticide Labels}

Those who use pesticides and who make decisions regarding their application should not only read the pesticide label but also interpret the meaning of label wording. See 
http://edis.ifas.ufl.edu/pi071 for more detail on interpreting pesticide label wording. Remember, when using pesticides, the label is the law.

All pesticide products (except exempt products that meet specific minimum-risk criteria) are registered by the EPA (EPA 2020). Each pesticide requires an extensive suite of testing to yield information concerning the hazards to people and to non-target organisms in the environment. Each pesticide is required to list precautionary and advisory statements on the label. The environmental hazards statement provides precautionary language informing users of the potential hazards to the environment from transport, use, storage, or spill of the product. These hazards may be to water, soil, air, beneficial insects, plants, or wildlife as identified in EPA risk assessments or when there is other information, such as accident history, indicating significant risks to non-target wildlife. Statements other than those listed may be required if more appropriate to the formulation or use.

In addition, non-target organism statements are required for each chemical. The Code of Federal Regulations title 40 (40 CFR) section 156.85 gives example statements that the EPA typically requires when data indicate certain acute toxicity levels for mammals, birds, fish, etc.: https://www. gpo.gov/fdsys/pkg/CFR-2012-title40-vol25/pdf/CFR2012-title40-vol25-sec156-85.pdf. The section also states:

"If a product is intended for or involves foliar application to agricultural crops, forests or shade trees, or mosquito abatement treatments, and contains a pesticide toxic to pollinating insects, the label must bear appropriate label cautions."

For an outdoor-use pesticide, a "bee hazard" warning may be required in the environmental hazard section of the label if the pesticide active ingredient or formulation is acutely toxic to honey bees $\left(\mathrm{LC}_{50}<11 \mu \mathrm{g} / \mathrm{bee}\right.$; see Table 1). Examples of pollinating insect hazard statements taken from the environmental hazards section of product labels include but are not limited to:

1. This product is toxic to bees exposed to treatment and for more than five days following treatment.

2. Do not apply this product to blooming, pollen-shedding, or nectar-producing parts of plants if bees may forage on plants during this time period, unless the application is made in response to a public health emergency declared by appropriate state or federal authorities.
3. This product is highly toxic to bees exposed to direct treatment or residues on blooming crops or weeds. Do not apply this product or allow it to drift to blooming crops or weeds if bees are visiting the treatment area.

4. This product is potentially toxic to honey bee larvae through residues in pollen and nectar, but not to adult honey bees. Exposure of adult bees to direct treatment or residues on blooming crops can lead to effects on honey bee larvae. See the "Directions for Use" section of this label for specific crop application instructions that minimize risk to honey bee larvae.

5. This product is toxic to bees exposed during the 3 hours following treatment. Do not apply this pesticide to blooming, pollen-shedding, or nectar-producing parts of plants if bees may forage on the plants during this time period.

6. Applications to all crops may be made at any time. This product is practically nontoxic to bees and wasps when used according to this label.

The EPA requires additional "Pollinator Protection Labeling" for pesticides, including all neonicotinoid class insecticides registered for foliar use outdoors. Starting in 2014, neonicotinoid product labels were required to have a pollinator protection portion that includes a "bee advisory box" with general information concerning routes of exposure and spray drift precautions and a "Directions for Use" portion that provides mitigation options for protecting pollinators from pesticide exposure. See Box 1 for information on neonicotinoid toxicity to bees.

Box 1.

\section{Neonicotinoids in Pest Control}

Controlling pests in agriculture, urban environments, and forests is a vital function we have as stewards of our environments. The use of pesticides is just one of many pest control strategies. It is important to remember the purpose of insecticides-they kill insects. Neonicotinoid chemistry, first developed in the 1990s, represents an advancement in insecticides. The chemical is based on the nicotine molecule, which has been altered so as not to impact human nerve endings but to retain its ability to impact insects. The chemical's ability to act systemically in the plant means that applicators do not need to spray broadly but instead can target pesticide applications. With systemic insecticides, the application method can improve pest management while minimizing direct contact with nontargets (e.g., via soil applications or injections). Additionally, the residual control nature of neonicotinoids means fewer applications are required, thus minimizing risk to the environment relative to frequent high-volume applications required for other pesticides (a common alternative). Thus far, the scientific data suggest that when neonicotinoids are used as described on the EPA-approved label, they are safer for humans, safer for the environment, and safer for non-target insects than many other pesticides available 


\section{Formulations}

In pesticides, the active ingredient is typically mixed with other ingredients to improve application, handling properties, and efficacy of the chemical. These are listed in percentage by weight on the label, although the specific other ingredients are not disclosed. The mixture of active ingredient (pesticide) and other ingredients (solvents, stabilizers, and adjuvants) is called the formulation. Product formulation can change the relative toxicity of a product with the same active ingredient. The following list includes the formulations that may pose hazards to bees and other pollinators. The formulations are listed in the general order of toxicity to bees from most toxic (microencapsulated pesticides) to least toxic (granular pesticides), though exceptions exist for each formulation (see Hooven et al. 2013).

- Microencapsulated insecticides tend to be more toxic to honey bees than other formulations. The active ingredient is encased in a polymer sphere similar to the size of a pollen grain that either abrades to release its contents or gradually disintegrates so that the active ingredient oozes out over time. Because of their size, these capsules are carried back to the colony and can remain toxic for long periods. The risk of drift with microencapsulated insecticides generally is low due to low application pressure.

- Dusts, similar to the size of pollen, stick to the bees and are generally more hazardous than liquid formulations. They carry a drift risk due to their fine particle size.

- Wettable powders (WP) have particles that form a suspension but do not dissolve in water. They can be applied as a liquid spray and are generally more hazardous than liquid formulations (EC or solutions). There is a low risk of drift if the liquid is applied at low pressure.

- Ultra-low-volume (ULV) formulations are usually more toxic than other liquid formulations because of the high concentration of active ingredient and high drift risk. High-concentration solutions are diluted by a powerful air flow into a large volume of air to produce a very fine droplet size prone to long distance drift. These droplets are readily removed from the air by adhering to foliage barriers.

- Emulsifiable concentrates (EC) and solutions or soluble powders are hazardous in that they are directly sprayed and can leave residues on foliage. The drift risk depends on application pressure and spray tip height.

- Seed coatings are applied directly to seeds. Bee exposure should be minimal, though the active ingredient can transfer to the talc carrier during planting. The resulting dust can drift onto blooming crops, weeds, adjacent habitat, etc.

- Generally, granular formulations are the least hazardous to bees because of their large size and low drift risk. Granular formulations are dissolved and activated during rain or irrigation, when bees are less active, and are distributed directly into the soil or thatch.

- Baits generally have lower impact on pollinators because they specifically target a pest that must ingest it.

Systemic insecticides can be delivered in any formulation, and they warrant additional consideration. They are usually applied to soils or foliage or are injected into the plant. The plant absorbs the active ingredient, which moves to growing tissues and may translocate to nectar, pollen, guttation droplets, and the excretion (honeydew) of sucking insects, all of which are available to foraging bees (Hooven et al. 2013).

\section{Approaches for Pesticide Applicators and Growers to Reduce Risks}

Pesticide applicators are required by law to follow the label. The pollinator protection language on the label was written to minimize product impact on pollinators. Consult with UF/IFAS Extension specialists if there are questions regarding the interpretation of pollinator protection provisions on labels. More information regarding bee protection for growers, can be found here: https://www.fdacs.gov/AgricultureIndustry/Bees-Apiary/Honey-Bee-Protection-in-Florida/ Bee-Protection-For-Growers.

Beyond complying with the label, the below-mentioned practices can aid in the protection of managed and non-managed pollinators and should be taken into consideration even if the farm, nursery, or landscape is not actively hosting honey bee colonies (or other managed bees) for supplemental pollination. Pest management varies by cropping system, so each recommendation below may not be applicable to every situation.

Use pesticides only when and where needed. Foraging honey bees, other pollinators, and beneficial arthropods are a natural resource, and their intrinsic value should be seriously considered. Vegetable, fruit, and seed crop yields in nearby fields can be adversely affected by reducing the population of pollinating insects and beneficial arthropods. It is always a good idea to check the agricultural field or pesticide application site for populations of both harmful 
and beneficial arthropods. Pesticides play an important role in IPM but should be used only when needed.

Develop a pest management plan that considers the likelihood of bees foraging during bloom. Labels for products that are toxic to bees may state that the applicator should not apply pesticides while crops are in bloom or may provide more specific instructions. Always carefully read and follow the instructions for pollinator safety. Such instructions may be found in the label's environmental hazards statement, the general use directions, or in cropspecific use instructions. Some labels may not contain bee protection statements and others may even allow applications during bloom under some circumstances. Still others may prohibit application during the bloom season. Consult UF/IFAS Extension or FDACS if you have questions about the meaning of label language.

Honey bees fly when the air temperature is above $55^{\circ} \mathrm{F}-$ $60^{\circ} \mathrm{F}\left(12.8^{\circ} \mathrm{C}-15.6^{\circ} \mathrm{C}\right)$ and are most active from 8 a.m. to 5 p.m. Always check a field for bee activity immediately before an application when the pesticide label bee protection statements apply. Evening applications, if allowed, may provide time for some pesticides to degrade or dry during the night, thereby reducing bee exposure when activity resumes the next morning. Be conscious of early days and longer hours in the peak of the summer, when bees will typically forage earlier and longer. Also, consider avoiding application during unusually low temperatures or when dew is forecast because under these conditions, sprays remain wet longer, and their residues can persist.

In general, ground applications are less hazardous to bees than are aerial applications. One should be sure not to spray open water sources or on-site apiaries directly. It is very important to reduce pesticide drift to non-target crops and vegetation. Drift-reducing application techniques (Figures 7A-7E) include increasing droplet size, reducing application spray pressure, using a low nozzle height, using drift-reduction nozzles, using drift-retardant adjuvants, and determining whether to use ground or aerial applications, avoiding applications during windy conditions, and using windbreaks, hedgerows, and vegetative buffers around crops. Policies prohibiting drift during windy conditions and buffer zones (e.g., "Do not apply this product when wind speed exceeds 10 miles per hour.") may appear on a product label (EPA 2001). These activities will reduce the incidence or severity of honey bee exposure to pesticides and aid in protecting non-managed pollinators. Although the above general rules can be helpful, remember, ultimately you are responsible for complying with the specific label instructions of the pesticide product you are using.
More detailed information on tactics to minimize drift may be found in http://edis.ifas.ufl.edu/pi232.

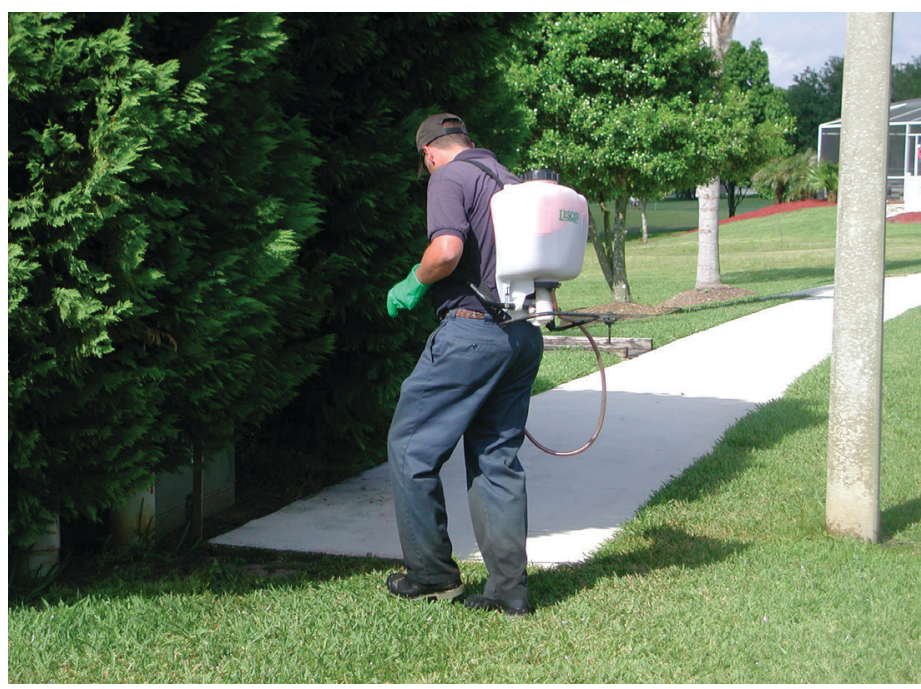

Figure 7A. Various methods of applying pesticides: Backpack sprayer Credits: Eileen Buss, University of Florida

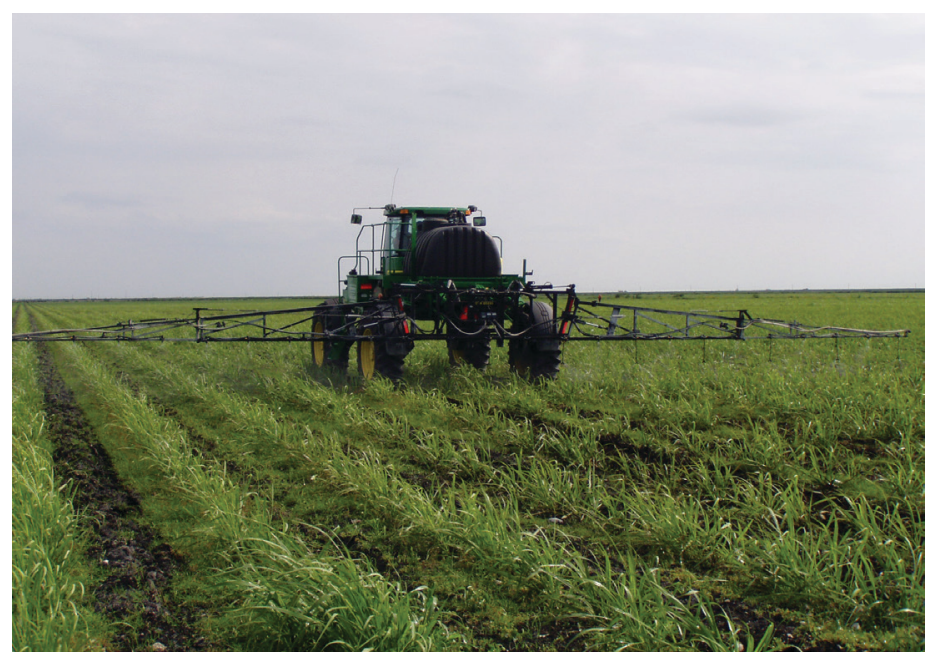

Figure 7B. Boom sprayer

Credits: UF/IFAS Pesticide Information Office

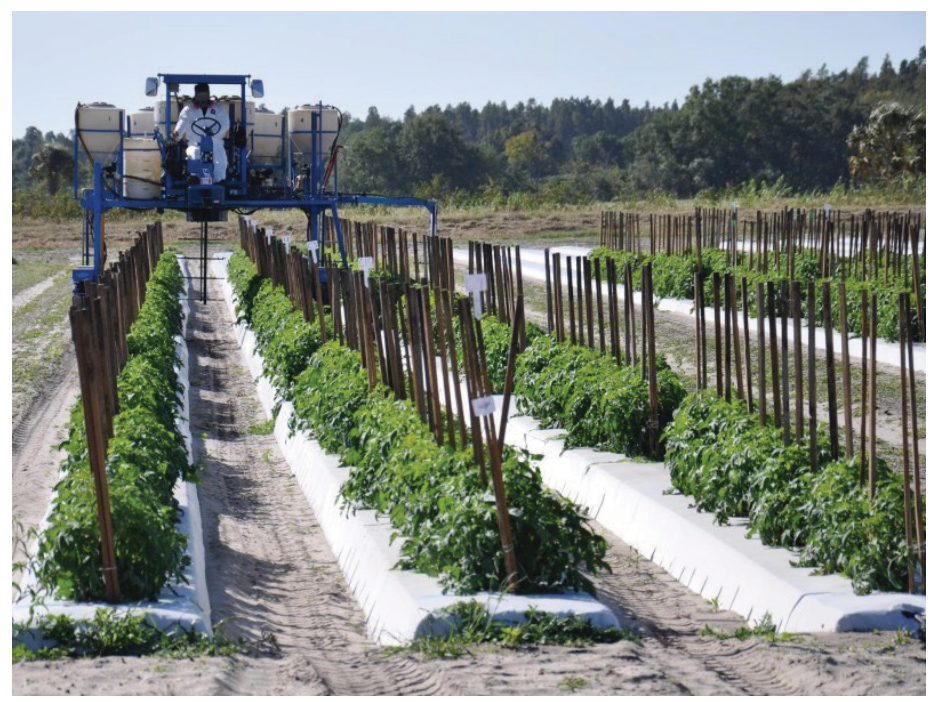

Figure 7C. High-clearance sprayer

Credits: Hugh Smith, University of Florida 


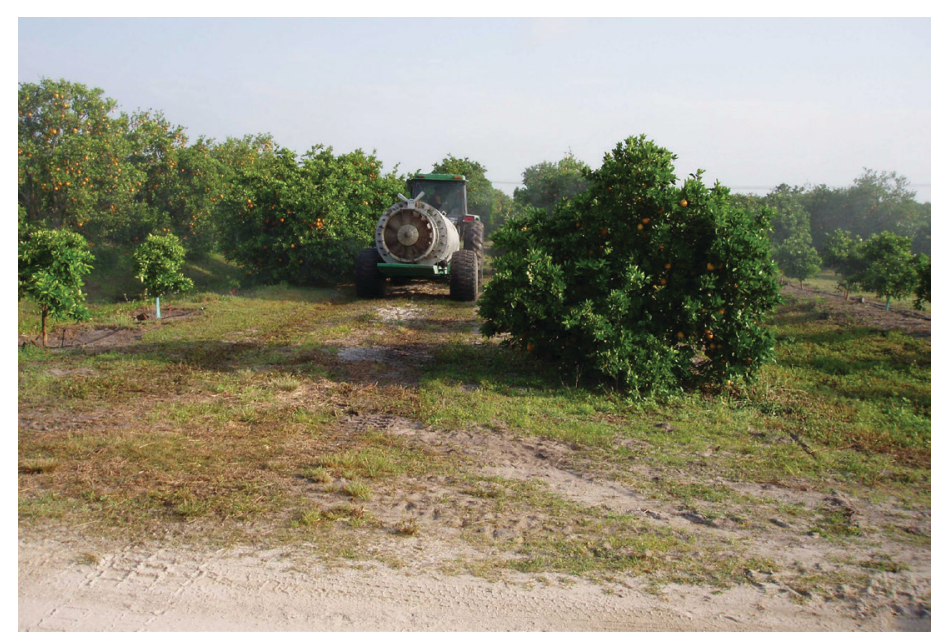

Figure 7D. Air-blast sprayer

Credits: UF/IFAS Pesticide Information Office

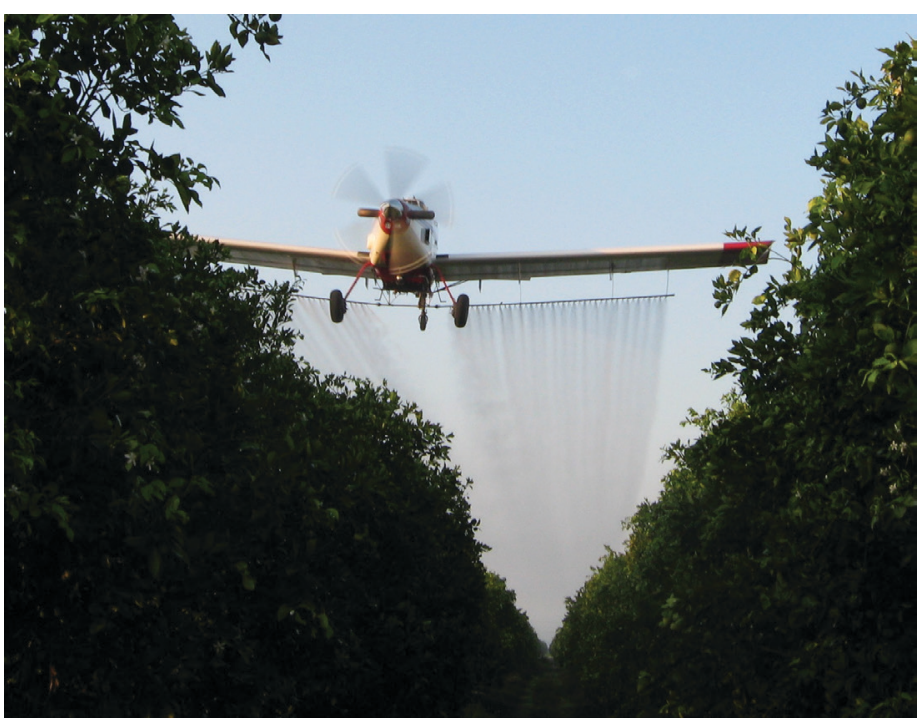

Figure 7E. Plane sprayer

Credits: Philip Stansly, University of Florida

Do not contaminate water. Bees require water to cool the hive. Avoid contaminating standing water with pesticides, and do not drain spray tank contents onto the ground so that they puddle. Be mindful that contaminated water can also come from drip irrigation being used for chemigation (application of pesticides through the use of irrigation), runoff, improper storage or spills, irrigation ditches, and leaking pipes.

Consider less toxic compounds. Some pest control situations allow the grower or pesticide applicator a choice of compounds to use. Products that are hazardous to honey bees must state so on the label. Where possible, choose products with low acute and residual toxicity to honey bees and other organisms. Always use caution with "broadspectrum" insecticides because of their general toxicity to all or most insects, including pollinators. Examples of broad-spectrum insecticide classes include pyrethroids, carbamates, organophosphates, etc. Some products, such as insect growth regulators, which generally have low adult bee toxicity, can be highly toxic to bee larvae. When in doubt, consult your local UF/IFAS Extension office specialist for details, recommendations, and further information about the toxicity of specific compounds to honey bees.

Consider less toxic formulations. The formulation of an insecticide can significantly change the toxicity of a compound to honey bees. A pesticide still may not be $100 \%$ safe for bees if the label does not include a Pollinator Protection Label. Remember that some pesticides may affect brood or produce unknown, long-term effects from low-dose, chronic exposure. Whenever possible, use formulations that are less hazardous to bees (see the hazardous rankings above in the "Formulations" section). Also, if the pesticide label and pest management programs allow, avoid tank mixing different classes of pesticides or applying premixes of more than one active ingredient. The synergistic effects of pesticides on bees and other pollinators are not well known and should be considered with caution. Theoretically, the impact of some tank mixes on pollinators may be more detrimental than the impact of these materials when applied alone (Fisher et al. 2017). Finally, consider lures and pheromones as alternatives to insecticides for pest management. Many products have been developed to target the mating of some insect pests and thus may be safer to bees than pesticides.

Non-crop application. Before treating an area with pesticides, determine the presence of blooming plants and weeds (such as clover, Spanish needle, etc.) that might attract bees (Figure 8). In some instances, bees have been killed even though the crop being sprayed was not in bloom. Some label statements restrict applications when weeds are in bloom. Attractive blooms in areas to be treated often can be mowed or otherwise removed (Larson et al. 2014, Environmental Toxicology and Chemistry), although mowing is not always the best option because it can destroy other beneficial insect habitat or force destructive insects into the crop being cultivated. Applicators should also be aware of pesticide drift to non-target vegetation, because the vegetation can serve as a refuge for pollinators and a supply of nesting materials for native bees.

Know your farm and your crop. Understanding your crop and its pollination requirements is one of the best tactics in deciding how to use pesticides and minimize the exposure to pollinators likely to be visiting your crop site and nearby areas. Understanding bloom times, pollination needs, and the environmental variables that affect them is crucial to developing a plan that protects honey bees and other pollinators while keeping pests at bay. Consider hiring an 
IPM professional or consult with your county Extension specialist for help identifying species of crop pests, their abundance, and life cycle.

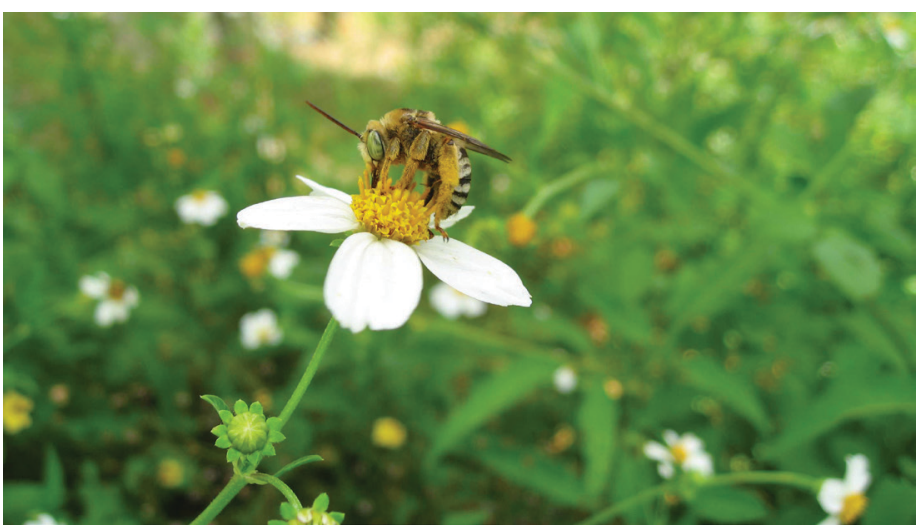

Figure 8. A Mellisodes sp. bee visiting Spanish needle (Bidens alba), a plant considered a weed but that is present in/around many agricultural fields. Spray drift to blooming weeds is dangerous to bees and other pollinators and should be avoided.

Credits: Katie Buckley, University of Florida

Conduct a native bee survey. Your crop may already be pollinated by unaccounted-for species of native bees. Your knowledge of the species and nesting preferences will aid in preventing unintended exposure. Crop-edges and vegetation patches within and surrounding planted areas on a farm provide habitat and additional forage for pollinators. Consider reducing herbicide applications in these areas because "weeds" can act as refuge and habitat for other pest-controlling beneficial insects. Consider planting vegetative buffers of non-noxious weeds and other nectar- or pollen-producing plants around crops and on-site apiaries to provide additional refuge and forage for bees and other pollinators. Protect the pollinators visiting the buffers by designating the buffers as no-spray zones. It is important to note that not all weeds are beneficial; some are sources of crop pests and pathogens, so it is best to conduct a farmscape analysis in collaboration with UF/IFAS Extension specialists when managing weeds for pollinators.

Notify beekeepers. If beekeepers are notified in advance of a pesticide application, they may be able to move colonies away from the treatment area, if desired. Florida law requires anyone keeping honey bees to be registered with the Florida Department of Agriculture and Consumer Services and all hives to be permanently marked with the beekeeper's firm number.

Agreements and notification. Cooperation between applicators, growers, beekeepers, Extension workers, and government officials is necessary to control problem crop pests and protect pollinators from pesticide exposure. The key to this cooperation is trust and constant communication among everyone involved. Protecting honey bees and other pollinators from pesticides can be difficult despite the fact that many of these chemicals are not considered hazardous to bees. There are many variables in the decision-making process leading to pesticide use, and the protection of pollinators is likewise a complicated undertaking. In general, pollinators die when pesticide applications are made based on insufficient information and/or made without regard to the safety of pollinators. It is highly recommended that growers and beekeepers develop a contract of agreement before placing honey bee colonies onto managed agricultural land. Some points to consider within this agreement include the number of hives and their placement, the duration of the colony presence, identification of temporary holding zones for when bees need to be moved, signage for no-spray or buffer zones, liability limitations for each party, and methods of contact (see next section for more information on agreements). You can find an example agreement here: https://edis.ifas.ufl. edu/aa169. Land managers and beekeepers must maintain an open line of communication throughout the season. If crop-specific or season-specific spray schedules are known, this information could be released to a beekeeper who may be interested in moving their hives onto the property. For resident honey bee colonies, this and additional advanced notification of intermittent pesticide application would allow honey bee colonies to be moved.

\section{Approaches for Beekeepers to Reduce Risks}

The FDACS conducted a series of meetings for beekeepers and citrus growers in 2013, out of which arose voluntary recommendations that both groups could follow to protect bees while also protecting citrus from damaging pests. Many of these recommendations are applicable to other crops.

- Develop and maintain direct communication with growers whose crops your bees are pollinating or from whose crops they gather nectar for honey production.

- Work with growers to reach written agreements providing permission to place hives close to crops for honey production or for crop pollination (see example agreement here: https://edis.ifas.ufl.edu/aa169). Beekeepers should be involved in the initial agreement writing and adhere to the points outlined. A new agreement should be drafted for each new crop, farm, or season because crop pests and their respective controls and effects on non-target pollinators will change. Include provisions that address:

- circumstances under which the grower will be free of liability; 
- the number of hives;

- how hives and bee yards will be marked by the beekeeper as required by law and to include any contact information requested by the grower;

- where hives will be placed so that they will not interfere with crop management and to reduce the likelihood of exposure of hives to pesticides;

- the duration of stay for the hives and when the stay will occur (identify a window during bloom when pesticide exposure is least likely);

- how the grower will provide a list of pesticide products intended to be used while hives are located in/adjacent to fields, if requested;

- how the grower will communicate plans to apply pesticides that may involve relocation of bee hives, if requested;

- identification of temporary holding areas where hives may be relocated during pesticide applications, if available;

- the beekeeper's liability insurance ( $\$ 1$ million is common coverage); and

- the best means for the beekeeper and grower to quickly contact one another if urgent issues arise.

- Beekeepers should take the time, upon disclosure of the pesticides to be used, to understand the label and potential hazards to bees. This information will allow the beekeeper to make a judgment on the potential risk of pesticide exposure and whether a given apiary location is ideal.

- Beekeepers should advise the grower immediately if they observe bee kills or any unusual bee conditions.

- Do not place bees in crops without a written agreement to do so from the grower. Property owners (and their agents) may contact FDACS-DPI if hives have been placed on their property without permission.

- When granted permission to keep hives in or by a crop, do not "sublet" by allowing other beekeepers to bring in their hives.

- Do not assume that because you have worked with a grower before you can bring your hives in again without written permission.

- Beekeepers should be available and ready to be on location to work with the grower as needs may arise.

- Keep the grower informed of hive locations, status, and concerns, and be willing to remove hives promptly if the need arises. If a pesticide application must occur while the bees are on site, the beekeeper should be willing and able to move the bees to the agreed-upon holding zone or out of the area altogether.

- Beekeepers should strive to understand the farm and crop dynamics of their chosen site.

- Hives should be escorted on and off the target bloom appropriately so that target pests can be treated during non-bloom times without risking damage to colonies.

- Follow regulations to register as a beekeeper with FDACS-DPI. All beekeepers in Florida are required to register their colonies with the FDACS-DPI Apiary Inspection section. Within that requirement, beekeepers are responsible for clearly marking all pieces of equipment with their firm number.

- Communicate with fellow beekeepers working in the area of the apiary to share information, facilitate communication with growers, encourage adoption of recommendations, facilitate movement of hives, and identify holding locations for temporary foraging.

- Be a good partner with growers. Be flexible and work to develop a long-standing relationship.

- If producing honey, reward growers who work with you. Consider financial remuneration or in-kind rewards.

- Recognize an apiary's total potential foraging area and inform neighboring growers within the area of the presence of the colonies. Additional knowledge of potential pesticide exposure within the foraging area would be of benefit.

- It is the responsibility of the beekeeper to contact their local Mosquito Control District (MCD) to report apiary locations and to request spray notifications, if applicable. Most mosquito control adulticide applications are done in the evening, thus presenting minimal risk to honey bees. For more information on MCDs and beekeeping, see http://edis.ifas.ufl.edu/in813.

\section{Hive Management}

- Proper hive management (Figure 9), including provision of a fresh source of water, supplemental feed (if necessary), and adequate monitoring of colony health, queen status, and pest/disease problems is of utmost importance.

- Adopt IPM practices to control hive pests and follow pesticide label directions for use. 


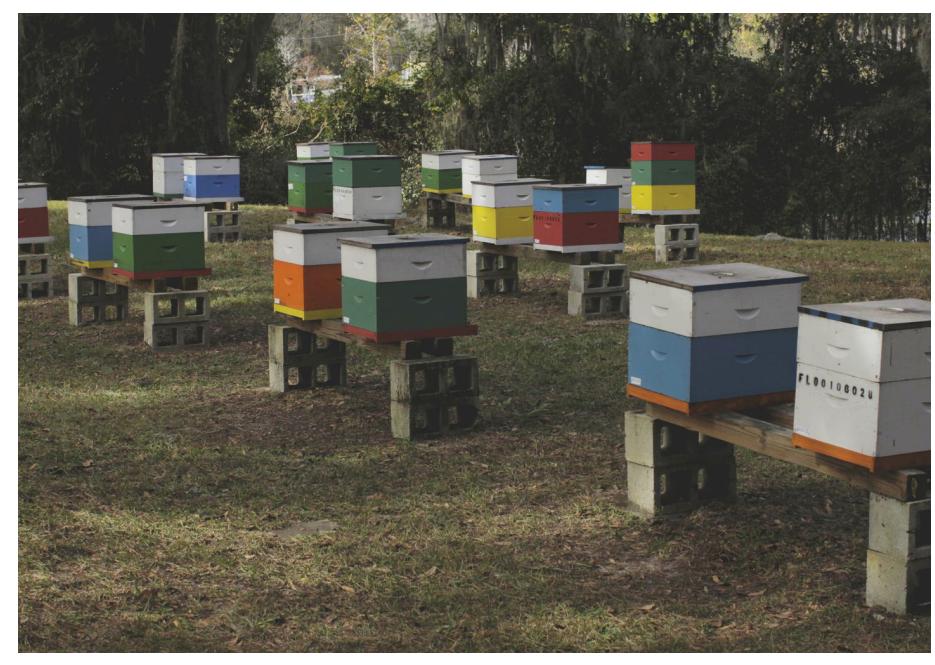

Figure 9. Properly managed hives should be maintained by the beekeeper. FDACS-DPI developed management recommendations for honey bee colonies. They can be found at http://www. freshfromflorida.com/Divisions-Offices/Plant-Industry/Bureaus-andServices/Bureau-of-Plant-and-Apiary-Inspection/Apiary-Inspection. Credits: James Hill (used with permission)

- Follow management recommendations developed by FDACS-DPI (https://www.fdacs.gov/Divisions-Offices/ Plant-Industry/Bureaus-and-Services/Plant-and-ApiaryInspection/Apiary-Inspection) and the UF/IFAS Honey Bee Research and Extension Laboratory.

- Place hives no sooner than early bloom, and remove promptly when bloom ends.

- Avoid periods when pest management activities may be required.

- Beekeepers should choose the least hazardous site within the farm for their hives, while not interfering with ordinary crop production operations. For example, hills pose less of a risk to bees than do valleys, which can concentrate falling spray drift. Hives set at least 500 feet from a roadway typically will avoid non-agricultural spraying for weed or mosquito control.

- Keep hives ready to relocate quickly, and have a plan of how and where to move them.

- Monitor hives frequently to assure bee needs are met.

- Keep colony health logs. They can be valuable if losses occur.

\section{Recognizing Mortality Due to Pesticide Exposure}

It is extremely difficult to pinpoint pesticide exposure as the cause of colony mortality. Honey bees are exposed to many stressors daily. Varroa and their associated pathogens, nutrition stress, and poor queen quality are reported to be the leading cause of honey bee decline in the country.
It is important to check mite levels to rule out pests/ disease as the cause of die-off before seeking other causes. Many times, acute exposure to pesticides by bees in the field (often when pesticides are sprayed during a daytime bloom) will cause an immediate lack of foraging bees, forager disorientation, and/or reduced foraging efficiency. Large numbers of dead, crawling, and walking bees at the hive entrance or intense fighting at the hive entrance can be an indication of acute poisoning. Poisoned bees will often appear confused with rapid movements, may be spinning on their backs, may appear to be "chilled," can become irritable (likely to sting) or paralyzed, or exhibit other abnormal behavior. Queens may be superseded (replaced by the workers) when a colony has been exposed to chronic pesticide doses. Lethargic, immobile bees may be unable to leave flowers or may exhibit abnormal hive dances (impaired communication).

One readily recognized symptom and good evidence of pesticide damage is the presence of many dead or dying bees near a colony's entrance. Dead and dying brood and newly emerged but dead workers are removed from the colonies and accumulate at the hive entrance. Acute pesticide exposure incidents will most often present a mass of dead and dying bees, the latter shaking and disoriented, in front of the hive. Acute pesticide exposure will tend to affect most or all of the hives in an apiary, not just one. In a short period of time, however, these dead bees may dry up and the remains be blown away and eaten by ants or other scavengers. A beekeeper who visits his or her yards only occasionally may not see these dead bees and thus may not be aware that his/her colonies have been acutely exposed. Chronic pesticide exposure may present itself as poor brood development or weakened colonies that die over winter. Again, regular colony maintenance and accurate logs will keep the beekeeper informed of potential incidences.

Some of these symptoms are not always distinct, and they cannot be taken as definite signs of pesticide poisoning. Many chronic management problems such as starvation, winter kill, chilled brood, or disease may present the same symptoms. These problems may be caused by pesticides in an indirect manner. It is difficult in many instances to state categorically that bees have been poisoned.

\section{Reporting Bee Losses}

Although it is sometimes difficult to detect poisoning of bees by pesticides, those cases that are clear-cut or borderline should be reported to the FDACS-DPI Apiary inspection services immediately. Beekeepers who suspect that their bees have been poisoned should look for and 
document any evidence of pesticide exposure. Affected beekeepers should be prepared to provide photos or video evidence of the incident, the magnitude of loss, any relevant apiary health status, previous self-applied pesticides (pesticides applied to the hive to control bee pests), firm number, apiary location, weather conditions of the date of incident, potential exposure route, and, if a particular pesticide product is suspected, its active ingredient and EPA registration number.

Florida is divided into apiary inspection districts. Beekeepers in each district are assigned to an apiary inspector. You can locate your local inspector's contact information by visiting https://www.fdacs.gov/Divisions-Offices/PlantIndustry/Bureaus-and-Services/Office-Locations/ApiaryInspector-Directory. If the DPI apiary inspector cannot determine other causes for the problem, he/she will contact the Division of Agricultural Environmental Services (AES) to conduct an investigation to determine if there was a misuse of pesticides that contributed to the bee losses. The apiary inspector will provide assistance with sample collection, and AES will conduct the investigation.

Beekeepers can also report suspected pesticide poisoning to the EPA, which has a cooperative program with the National Pesticide Information Center and Oregon State University that provides an online program where anyone can report an ecological (or other) pesticide incident (http://npic.orst.edu/contactus.html). The main rule to follow when completing the incident report is to be as specific and descriptive as possible.

\section{The Future}

The future sustainability of honey bees and agriculture depends on defining and respecting the complex relationship between bees and pesticides. Agricultural pest management schemes and the use of chemical pesticides to combat sometimes-crippling crop pests must be attempted cautiously and in balance with the intrinsic value of the native and honey bee pollinators. In many cases, the success of one is tied to that of the other. Implementation of the outlined risk-reducing strategies in this document and use of the explanations of the laws, labels, and associated definitions will help all parties move forward with a better understanding of this delicate balance. There is no doubt that communication between beekeepers and growers and other pesticide applicators is the best line of defense in protecting honey bees and other pollinators from harmful exposure to pesticides.

\section{References}

Calderone, N. W. 2012. "Insect Pollinated Crops, Insect Pollinators and US Agriculture: Trend Analysis of Aggregate Data for the Period 1992-2009." Plos One 7:e37235.

Delaplane, Keith, and D. F. Mayer. 2000. "Crop Pollination by Bees." Entomol Experiment Applic. 99. https://doi. org/10.1079/9780851994482.0000

Ellis, J. D., and J. Hayes. 2008. Mosquito Control and Beekeepers. ENY-149. Gainesville: University of Florida Institute of Food and Agricultural Sciences. https://edis.ifas. ufl.edu/in813

EPA. 2001. Spray and Dust Drift Label Statements for Pesticide Products. https://www.epa.gov/pesticide-registration/ prn-2001-X-draft-spray-and-dust-drift-label-statementspesticide-products

EPA. 2012. Pollinator Risk Assessment Framework Agency White Paper. http://www.regulations. gov/\#!documentDetail;D=EPA-HQ-OPP-2012-0543-0004

EPA. 2020. Conditions for Minimum Risk Pesticides. https://www.epa.gov/minimum-risk-pesticides/ conditions-minimum-risk-pesticides

Fishel, F. M. 2005. Interpreting Pesticide Label Wording. PI-34. Gainesville: University of Florida Institute of Food and Agricultural Sciences. http://edis.ifas.ufl.edu/pi071

Fishel, F. M., and J. A. Ferrell. 2010. Managing Pesticide Drift. PI-232. Gainesville: University of Florida Institute of Food and Agricultural Sciences. http://edis.ifas.ufl.edu/ pi232

Fisher, Adrian II, Chet Coleman, Clint Hoffmann, Brad Fritz, and Juliana Rangel. 2017. "The Synergistic Effects of Almond Protection Fungicides on Honey Bee (Hymenoptera: Apidae) Forager Survival" Journal of Economic Entomology 110 (3): 802-808. https://doi.org/10.1093/jee/ tox031

Fisher, A. II, and J. Rangel. 2018. "Exposure to Pesticides during Development Negatively Affects Honey Bee (Apis mellifera) Drone Sperm Viability." PLoS ONE 13 (12): e0208630. https://doi.org/10.1371/journal.pone.0208630

Gradish et al. 2019. "Comparison of Pesticide Exposure in Honey Bees (Hymenoptera: Apidae) and Bumble Bees (Hymenoptera: Apidae): Implications for Risk Assessments." Environmental Entomology. 48 (1): 12-21. 
Hooven, L., R. Sagili, and E. Johansen. 2013. How to Reduce Bee Poisoning from Pesticides. PNW 591. Pacific Northwest Extension Publication. Oregon State University, University of Idaho, Washington State University, 35 pp.

Johnson, R. M., M. D. Ellis, C. A. Mullin, and M. Frazier. 2010. "Pesticides and Honey Bee Toxicity-USA.” Apidologie 41:312-331. https://doi. org/10.1079/9780851994482.0000

Mortensen, A. N., D. R. Schmehl, and J. Ellis. 2013. European honey bee Apis mellifera Linnaeus, and subspecies (Insecta: Hymenoptera: Apidae). EENY568. Gainesville: University of Florida Institute of Food and Agricultural Sciences. https://edis.ifas.ufl.edu/in1005

Mullin, C. A., M. Frazier, J. L. Frazier, S. Ashcraft, R. Simonds, D. vanEngelsdorp, and J. S. Pettis. 2010. "High Levels of Miticides and Agrochemicals in North American Apiaries: Implications for Honey Bee Health." PLoS One 5:e9754. https://doi.org/10.1371/journal.pone.0009754
Ostiguy, N., Drummond, F. A., Aronstein, K., Eitzer, B., Ellis, J. D., Spivak, M., and Shepherd, W. S. 2019. "Honey Bee Exposure to Pesticides: A Four-Year Nationwide Study." Insects 10 (1): 13. https://doi.org/10.3390/insects10010013

Sanchez-Bayo, F, and K. Goka. 2014. "Pesticide Residues and Bees-A Risk Assessment.” PLoS ONE 9 (4): e94482. https://doi.org/10.1371/journal.pone.0094482

Thompson, H. M. 2001. "Assessing the Exposure and Toxicity of Pesticides to Bumblebees (Bombus sp.)." Apidologie 32:305-321.

Winston, M. L. 1987. The Biology of the Honey Bee. Harvard University Press, Cambridge, Massachusetts, USA. 281 pp.

Wu, J. Y., C. M. Anelli, and W. S. Sheppard. 2011. "SubLethal Effects of Pesticide Residues in Brood Comb on Worker Honey Bee (Apis mellifera) Development and Longevity." PLoS ONE 6 (2): e14720. https://doi.org/10.1371/ journal.pone.0014720

Table 1. Honey bee toxicity groups and precautionary statement.*

\begin{tabular}{|c|c|c|}
\hline Toxicity group & $\begin{array}{l}\text { Precautionary statement if extended } \\
\text { residual toxicity is not displayed }\end{array}$ & $\begin{array}{c}\text { Precautionary statement if extended residual } \\
\text { toxicity is displayed }\end{array}$ \\
\hline $\begin{array}{l}\text { I-Product contains any active } \\
\text { ingredient with acute } \mathrm{LD}_{50} \text { of } \leq 2 \\
\text { micrograms/bee. }\end{array}$ & $\begin{array}{l}\text { This product is highly toxic to bees exposed to } \\
\text { direct treatment on blooming crops or weeds. } \\
\text { Do not apply this product or allow it to drift } \\
\text { to blooming crops or weeds while bees are } \\
\text { actively visiting the treatment area. }\end{array}$ & $\begin{array}{l}\text { This product is highly toxic to bees exposed to direct } \\
\text { treatment or residues on blooming crops or weeds. Do } \\
\text { not apply this product or allow it to drift to blooming } \\
\text { crops or weeds if bees are visiting the treatment area. }\end{array}$ \\
\hline $\begin{array}{l}\text { II-Product contains any active } \\
\text { ingredient(s) with acute } \mathrm{LD}_{50} \text { of } \\
>2 \text { micrograms/bee but }<11 \\
\text { micrograms/bee. }\end{array}$ & $\begin{array}{l}\text { This product is toxic to bees exposed to direct } \\
\text { treatment. Do not apply this product while } \\
\text { bees are actively visiting the treatment area. }\end{array}$ & $\begin{array}{l}\text { This product is toxic to bees exposed to direct } \\
\text { treatment or residues on blooming crops or weeds. } \\
\text { Do not apply this product if bees are visiting the } \\
\text { treatment area. }\end{array}$ \\
\hline III-All others. & No bee caution required. & No bee caution required. \\
\hline
\end{tabular}

